\title{
Alte und neue Mythen um den Schwangerschaftsabbruch
}

\author{
Choon-Kang Walther ${ }^{a}$, Helene Huldi ${ }^{b}$ \\ a Dr. med., Fachärztin für Gynäkologie und Geburtshilfe, Mitglied FMH, Mitglied APAC Suisse \\ ${ }^{b}$ Fachärztin für Gynäkologie und Geburtshilfe, Mitglied FMH, Mitglied APAC Suisse, Frauenpraxis Runa
}

Seit 2002 gilt in der Schweiz der straffreie Schwangerschaftsabbruch (SAB) während der ersten 12 Schwangerschaftswochen (SSW) seit dem ersten Tag der letzten Periode (= Fristenregelung). Das Stimmvolk hat 2014 einen Angriff auf die Bezahlung durch die Krankenkasse deutlich abgelehnt (fast 70\% stimmten gegen die «Privatfinanzierung»). In der Schweiz werden Themen wie Sexualität und die Verhütung ungewollter Schwangerschaft sehr offen diskutiert. Verhütungsmittel (Antikonzeptiva) sind problemlos erhältlich. Dadurch liegt die Zahl der Schwangerschaftsabbrüche in der Schweiz bei gebärfähigen Frauen (15-44 Jahre, Bundesamt für Statistik, 2014) bei 6,3 SAB pro 1000 Frauen, am tiefsten in Europa und wahrscheinlich weltweit. Trotzdem werden betroffene Frauen immer wieder mit unzeitgemässen Aussagen konfrontiert. Einige Mythen rund um das Thema Schwangerschaftsabbruch halten sich in der Ärzteschaft hartnäckig. Wir möchten diesem Umstand ein paar Fakten entgegenhalten.

"Durch die Einführung von Mifegyne (RU 486) ist die Zahl der Schwangerschaftsabbrüche angestiegen.» Falsch: Mifegyne wurde im November 1999 eingeführt. Die Zahl der SAB in der Schweiz war im Jahr 199012 986,

\footnotetext{
Anciens et nouveaux mythes autour de l'interruption de grossesse L'interruption de grossesse pendant les 12 premières semaines à compter du premier jour des dernières menstruations (= régime du délai) est admise en Suisse depuis 2002. En 2014, le peuple suisse a catégoriquement refusé $(70 \%$ des votants se sont prononcés contre un financement privé de l'avortement) l'attaque contre le remboursement de l'avortement par les caisses-maladie. En Suisse, la sexualité, la contraception et les grossesses non désirées sont ouvertement discutées et l'accès aux contraceptifs ne pose pas de problèmes. Le nombre d'interruptions de grossesse y est le plus bas d'Europe et probablement du monde (6,3/1000 femmes de 15-44 ans). Malgré tout, les femmes concernées sont régulièrement confrontées à des remarques d'un autre âge. Le présent article porte sur quelques mythes autour de l'interruption de grossesse toujours d'actualité dans le monde médical.
}

im Jahr 200012278 und im Jahr 2014 10 246, also sinkend. Dies bei steigenger Wohnbevölkerung. Die Rate der SAB pro 1000 Frauen zwischen 15 und 44 Jahren war 2010 knapp über 7, 2014 lag sie bei 6,3 SAB pro 1000 Frauen.

\section{"Ein medikamentöser SAB kann nur bis 7+O Schwan-} gerschaftswochen (SSW) durchgeführt werden.» Falsch: Gemäss dem Expertenbrief Nr. 15 der Schweizerischen Gesellschaft für Gynäkologie und Geburtshilfe (SGGG) (überarbeitet 16. Dezember 2008) ist Mifegyne zum Schwangerschaftsabbruch in einem höheren Schwangerschaftsalter, zum Beispiel bis zum 63. Tag anwendbar. Grosse Fallzahlen aus dem Ausland belegen, dass die Methode erfolgreich ist. Bei der Abortinduktion aufgrund von Fehlbildungen des Fötus wird Mifegyne in der Schweiz auch im 2. Trimenon angewendet.

\section{«Ein legaler SAB darf nur bis 12+O SSW durchgeführt werden. Danach machen sich die Ärztin und die Frau strafbar."}

Falsch: Über 12+0 SSW gilt die medizinische Indikation. Das heisst, es braucht ein ärztliches Attest. Dieses bescheinigt der Frau eine gesundheitliche Gefährdung durch Fortführen der Schwangerschaft. Im Wortlaut: «Der Abbruch einer Schwangerschaft ist straflos, wenn er nach ärztlichem Urteil notwendig ist, damit von der schwangeren Frau die Gefahr einer schwerwiegenden körperlichen Schädigung oder einer schweren seelischen Notlage abgewendet werden kann. Die Gefahr muss umso grösser sein, je fortgeschrittener die Schwangerschaft ist.»

\section{«Nach 12+O SSW darf ein Schwangerschaftsabbruch} durchgeführt werden, sofern ein psychiatrisches Gutachten vorliegt."

Falsch: Jede Ärztin kann die Indikation für einen Schwangerschaftsabbruch nach $12+0 \mathrm{SSW}$ stellen. Es braucht hierzu kein Gutachten, jedoch eine sorgfältige Dokumentation der Gründe für den Schwangerschaftsabbruch, welche die seelische Notlage oder die Ge- 


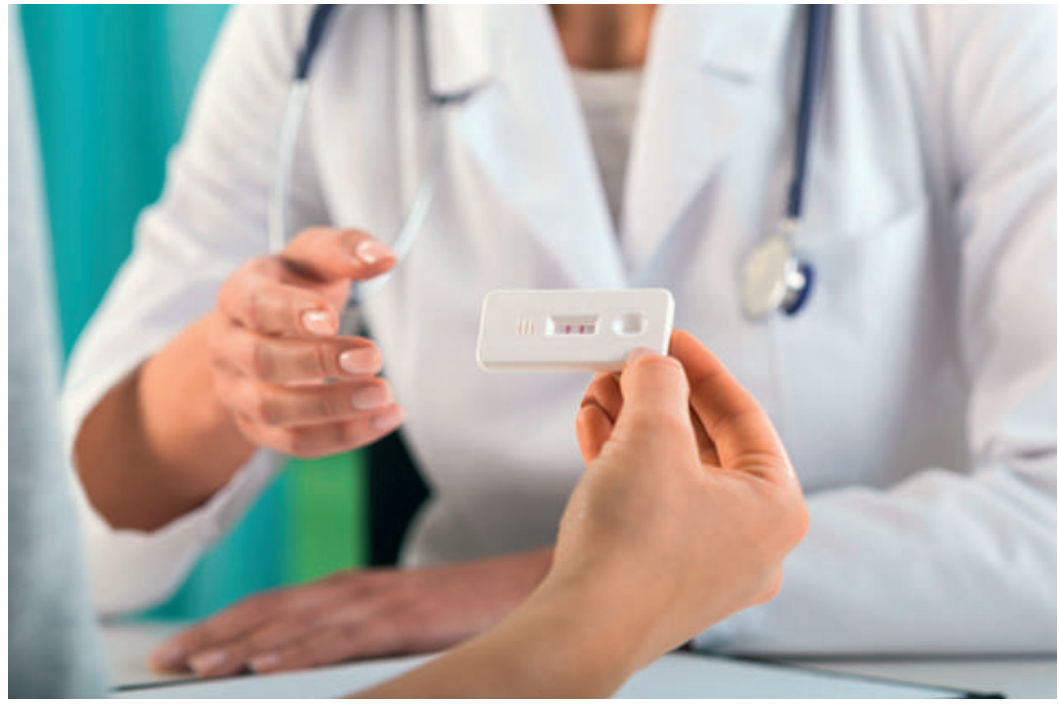

In der Schweiz werden Sexualität und ungewollte Schwangerschaft offen diskutiert. Trotzdem werden Frauen, die sich überlegen, einen Abbruch vornehmen zu lassen, immer wieder mit unzeitgemässen Aussagen konfrontiert.

sundheitsgefährung der Frau beim Weiterführen der Schwangerschaft bestätigen.

«Die Indikation für den SAB muss von einer weiteren Ärztin bestätigt werden.»

Falsch: Die Ärztin, die den SAB durchführt, darf auch selber die Indikation stellen.

\section{«Ein chirurgischer SAB wird immer im Spital durch- geführt."} ausgewählten Ärztinnen ist eine sichere Alternative. Statt in Vollnarkose oder Spinalanästhesie wird der Eingriff in Lokalanästhesie durchgeführt. Dadurch sinkt das Risiko einer Blutung während dem Eingriff und das Anästhesierisiko ist tiefer. Zudem wird die Patientin vom ihr bereits bekannten Team in der Praxis betreut. Das Setting in der Praxis umfasst weniger Personal als in einer Klinik mit unbekannten Ärzten, Anästhesie-, OP- und Pflegefachleuten.

Korrespondenz:

Dr. med. Choon-Kang

Walther und Helene Huldi

Frauenpraxis Runa

Theatergasse 26

$\mathrm{CH}-4500$ Solothurn

mythenzumsab[at]drckw.ch

«Ein SAB darf erst durchgeführt werden, wenn eine intakte intrauterine Schwangerschaft mit Ultraschall bestätigt ist. Sonst besteht u.a. die Gefahr der persistierenden Eileiterschwangerschaft."

Falsch: Ein Schwangerschaftsabbruch kann früher durchgeführt werden. Wenn keine intakte Schwanger-
Falsch: Ein chirurgischer SAB in der Arztpraxis von

schaft oder noch gar kein Embryo intrauterin gesehen wurde, muss nach dem SAB das Absinken des BetaHCG im Serum kontrolliert werden.

"Zwischen dem ersten Arztbesuch und dem SAB muss eine mindestens 24-stündige Bedenkzeit eingehalten werden."

Falsch: Die Dauer der Bedenkzeit ist im Gesetzestext nicht definiert. «Es muss eine angemessene Bedenkzeit eingehalten werden». Die Frauen kommen oft schon gut informiert und nach reiflicher Überlegung und Besprechung mit Angehörigen zur ersten Konsultation wegen ungewollter Schwangerschaft.

Die Abgabe von Mifegyne bei der ersten Konsultation ist möglich. Da die Informationen über das medizinische Prozedere, welche der Frau mitgeteilt werden, komplex sind, ist eine zweite Konsultation oft sinnvoll.

\section{«Das Ausstossen des Schwangerschaftsproduktes muss immer im Spital oder in einer Arztpraxis erfolgen."}

Falsch: Das Ausstossen der Schwangerschaft kann zu Hause erfolgen. Viele Frauen schätzen jedoch medizinische Betreuung während dem Ausstossen der Schwangerschaft. Besonders junge, nullipare Frauen profitieren bei starken Blutungen oder starken Schmerzen. Wenn das Ausstossen der Schwangerschaft zu Hause erfolgen soll, ist eine ausführliche Aufklärung und die Abgabe von Notfall-Telefonnummern wichtig.

\section{"Die Nachkontrolle beinhaltet immer Ultraschall.»}

Falsch: Bei Ultraschall kurz nach dem SAB findet sich Restmaterial. Es ist nach wie vor unklar, wo die zulässige Grenze der Endometriumdicke ist. Die Beta-HCGKontrolle zwei Wochen nach dem SAB ist die bessere Methode. Bei Beta-HCG über 500-1000 IU/l muss interveniert werden. Es gibt auch einen Schwangerschaftstest (Check-ToP), der die Grenze bei 1000 IU/l hat.

Bildnachweis (c) Bialasiewicz | Dreamstime.com

Hinweis

Der Einfachheit halber wird nur die weibliche Form gewählt. Sie soll für beide Geschlechter gelten. 